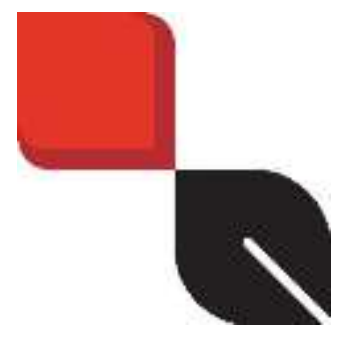

Cuadernos del CILHA n 34 - 2021 | publicación continua

ISSN 1515-6125 | EISSN 1852-9615

http://revistas.uncu.edu.ar/ojs/index.php/cilha/

CC BY-NC 2.5 AR

Recibido: 07/06/2021 Aprobado: 15/06/2021

PP. 1-25

DOI: https://doi.org/10.48162/rev.34.015

\title{
El film La Llorona de Jayro Bustamante: memoria cultural y género en la justicia transicional guatemalteca
}

\section{The film La Llorona de Jayro Bustamante: Cultural Memory and Gender in the Guatemalan Transitional Justice}

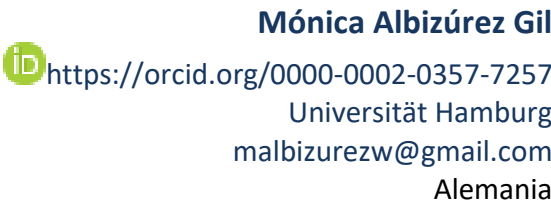

Resumen: Este trabajo se centra en el análisis del film La Llorona (2019), dirigido por el cineasta guatemalteco Jayro Bustamente y cuyo título, en clave de leyenda popular, alude a la mujer que ahogó a sus hijos y, como consecuencia de la culpa, los busca por las noches cerca de los ríos y los pueblos. La Llorona es, en esa película, una mujer indígena que ha sobrevivido al genocidio guatemalteco y que, como empleada doméstica, ingresa en la casa del general Enrique Monteverde, quien funciona como el alter ego del general Efraín Ríos Montt (1926-2018). La película se centra en los días en que el general Monteverde es acusado por el delito de genocidio, siendo fundamental en consecuencia en mi análisis la representación de las víctimas mujeres indígenas como también la puesta en escena de la convivencia jerárquica en el espacio de la casa. Como sostiene la antropóloga Aura Cumes, en ese espacio perdura un poder de dominación entre las mismas mujeres, bajo la relación jerárquica "señora-muchacha". Mi objetivo es examinar 
cómo se representan en el film el alcance y las limitaciones de la justicia transicional guatemalteca con relación a las mujeres víctimas del genocidio y, ligado a ello, las reconciliaciones simbólicas de clase y de género que se proponen.

Palabras clave: Representación, Genocidio, Género, Justicia transicional, memoria cultural.

Abstract: This paper focuses on the analysis of the film La Llorona (2019), directed by Guatemalan filmmaker Jayro Bustamente and whose title, according to the popular legend, alludes to the woman who drowned her children and, as a result of guilt, searches for them at night near rivers and villages. La Llorona is, in this film, an indigenous woman who survived the Guatemalan genocide. As a maid, she enters in the house of General Enrique Monteverde, who functions as the alter ego of General Efraín Ríos Montt (19262018). The film focuses on the days in which General Monteverde is accused of the crime of genocide, being fundamental in my analysis the representation of the indigenous female victims, as well as the staging of the hierarchical coexistence in the space of the house. As anthropologist Aura Cumes argues, a power of domination among the women themselves persists in this domestic space, under the hierarchical relationship "señoramuchacha". My goal is to examine how in the film the film represents the scope and limitations of Guatemalan transitional justice in relation to the women victims of the genocide and, linked to this, the symbolic reconciliations of class and gender that are proposed.

Keywords: Representation, Genocide, Gender, Transitional justice, Cultural memory.

\section{Justicia transicional: referencias históricas para entender el film La Llorona}

Para comprender el argumento de la película y sus dimensiones simbólicas, es necesario discutir la importancia y, a la vez, las limitaciones del proceso penal por el delito de genocidio seguido en 2013 contra del general Efraín Ríos Montt quien, no obstante haber gobernado solamente 18 meses -de marzo de 1982 a agosto de 1983durante el prolongado conflicto armado guatemalteco (1960-1996), impulsó una de las más sanguinarias políticas de contrainsurgencia (Comisión para el Esclarecimiento Histórico, \#1792). El informe "Nunca más" del conocido Informe Proyecto Interdiocesano de Recuperación de la Memoria Histórica, el llamado REHMI, documenta el mayor número de masacres en contra de la población maya durante el régimen de Ríos Montt, en el Ilamado “Plan de Campaña Victoria 82" que tenía por

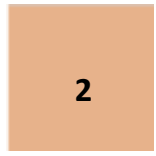

Cuadernos del CILHA n $34-2021$

ISSN 1515-6125 | EISSN 1852-9615

CC BY-NC 2.5 AR

http://revistas.uncu.edu.ar/ojs/index.php/cilha/ 
objetivo desarticular el apoyo social de la guerrilla ${ }^{1}$. Una de las mayores ofensivas se llevó a cabo en contra de las poblaciones ixiles, uno de los veintidós grupos étnicolingüísticos de Guatemala ${ }^{2}$. Aunque el proyecto del REHMI iba a incluir una segunda etapa centrada en establecer responsabilidades individuales por violaciones a los derechos humanos (que tampoco fueron determinadas en el marco de la Comisión para el Esclarecimiento Histórico), tal acción no se llevó a cabo porque 48 horas después de presentado el informe, Monseñor Juan Gerardi -artífice de aquel proyecto- fue asesinado ${ }^{3}$.

De tal manera, dentro del concepto de justicia transicional, como formas de transitar de periodos de conflicto y represión a enfrentar violaciones de derechos humanos que superan el sistema judicial convencional (ver The International Center for Transitional Justice ICTJ), no tuvo lugar una persecución penal de los responsables en los años posteriores a la firma de los Acuerdos de Paz (1996). En consecuencia, la importancia del juicio contra Ríos Montt radica en que, por primera vez, un jefe de estado de Guatemala era imputado y procesado por delitos en contra de derechos humanos en el fuero interno del país (Oglesby y Nelson, 2016; Benítez Jiménez, 2019)4. El juicio

\footnotetext{
${ }^{1}$ A diferencia de la $\mathrm{CEH}$, este proyecto coordinado por la Oficina de Derechos Humanos del Arzobispado de Guatemala de la Iglesia Católica (ODHAG) sí provocó una mayor participación y recepción de la sociedad guatemalteca. Un factor decisivo fue la participación de 42,275 testimoniantes que fueron escuchados y grabados en español y lenguas mayas. Esta convocatoria positiva tuvo que ver, entre otros factores, porque los entrevistadores "eran habitantes de las propias comunidades, lo cual facilitó no solo el acceso y la confianza de la gente, sino además un sentido de reconstrucción del tejido social” (XXIII Tomo I).

${ }^{2}$ La CEH indica en el numeral 3581 que en el área Ixil se afectó en un $97.80 \%$ al pueblo maya.

${ }^{3}$ Este asesinato y sus dimensiones políticas en el tema del memoria queda analizado en el reportaje literario de investigación llevado a cabo por Francisco Goldman, The Art of Political Murder (2007), como en el documental que basa en dicho libro y producido por HBO con el mismo nombre en 2020.
}

${ }^{4}$ Este proceso también se entabló contra José Mauricio Rodríguez Sánchez, jefe de la inteligencia militar durante el régimen de Efraín Ríos Montt. Los estudios son coincidentes que tal proceso en la jurisdicción nacional fue posible por los esfuerzos de largos años de la sociedad civil, pero también por una mayor independencia del Ministerio Público bajo las jefaturas asumidas por Amílcar Velásquez Zarate en 2008 y Claudia Paz y Paz en 2010. El tribunal que tuvo a su cargo la causa en contra de Efraín Ríos Montt fue integrado por los jueces Patricia Bustamante García, Pablo Xitumul de Paz y Yassmín Barrios Aguilar, quien además lo

Cuadernos del CILHA n $34-2021$ 
permitió no solo la testificación de las víctimas en idiomas español y mayas, sino también el suministro de pruebas forenses así como las declaraciones de científicos sociales sobre las lógicas que operaron en el conflicto armado guatemalteco con el objeto de probar la consecución de un genocidio. Como sostiene Oglesby y Nelson (2016), la defensa no se concentró en refutar los cargos sino en dos estrategias: retrasar la sentencia por medio de amparos y propiciar una oposición al juicio en la opinión pública. Antiguos jefes militares y sus redes familiares jugaron un papel preponderante en generar esa oposición. El delito imputado al general Ríos Montt, el delito de genocidio, no solo fue objetado en los medios por militares y ex militares, sino también por importantes asociaciones, líderes políticos y académicos que argüían tres razones para desestimar tal delito: la motivación de acciones militares estaba enfocada en derrotar a la guerrilla y no poblaciones mayas, hubo personas de origen maya (patrulleros civiles) que formaron parte del ejército y, durante el largo conflicto armado, las víctimas no se limitaron a esa identidad maya (Oglesby y Nelson, 2016).

La sentencia condenatoria en contra de Ríos Montt, no obstante, se basó en un criterio claro: la motivación última del ejército era derrotar a la guerrilla, pero para ello la política de contrainsurgencia se dirigió intencionalmente a grupos étnicos, como los mayas ixiles, que se consideraron enemigos internos del Estado. De tal manera, en este planteamiento fue clave vincular la política contrainsurgente con el racismo estructural que ha caracterizado al Estado guatemalteco desde la fundación nacional en el siglo XIX. Por lo tanto, a pesar de que la sentencia condenatoria fue revocada 10 días después por la Corte de Constitucionalidad, en una clara motivación política, el proceso judicial tuvo un efecto simbólico en la sociedad guatemalteca en cuanto a crear una legitimidad respecto del reconocimiento las víctimas (Benítez Jiménez, 2019; Burt, 2016) y también en la centralidad otorgada a los delitos de guerra en contra de las mujeres en la configuración del delito de genocidio:

One of the most important aspects of the 10 May verdict was the centrality of gendered war crimes as part of the genocide. The judges' decision to link sexual

presidió. Yassmín Barrios ya había juzgado dos importantes procesos en el campo de derechos humanos: el entablado por el asesinato de la antropóloga Myrna Mack y por el asesinato del Monseñor Juan Gerardi. 
violence to a strategy to destroy the Maya Ixil ethnic group creates a judicial precedent that will likely be important in future international discussion of these types of crimes. (Olgeby y Nelson, 2016, p. 138)

Ahora bien, como consensuan Crosby et al. (2016), basándose en las reflexiones de Sharon Marcus, los testimonios sobre violencia sexual en el foro judicial por sí solos resultan problemáticos, pues pueden reducirse a "prized rape scripts" que favorecen una sentencia condenatoria, sin tomar en cuenta historias más complejas de resistencia y reparación. La reparación se entiende como "the psychological state in which victims feel that adequate amends have been made for a wrong committed" (Hamber, 2009, p. 97). Desde este entendimiento, un daño derivado del genocidio resulta irreparable, pero dentro del espectro de acciones posibles para producir aquel estado psicológico de la víctima a que se refiere Hamber (2009), el Estado de Guatemala apenas ha proporcionado una limitada ayuda material, precedida de complejos trámites burocráticos. Este patrón se repite en los demás casos judiciales por delitos cometidos en el conflicto armado, de tal manera que las condiciones de precariedad y de racismo de las víctimas no han cambiado ${ }^{5}$. Crosby et al. (2016) puntualizan la necesidad de conceptualizar esa pobreza y racismo no como contextos de las víctimas, sino como parte integrante de su identidad y, con base en ello, definir los alcances de la reparación.

Por otra parte, durante el proceso por genocidio también se rindieron testimonios sobre una voluntad de exterminar niños. "Witness testimony revealed the army's intention to exterminate children, including infants and unborn fetuses" (Burt, 2016, p. 147). Algunos de los infantes sobrevivientes fueron capturados por el ejército y luego dejados en orfanatos. Relacionado con el proceso de genocidio, es necesario mencionar para el análisis del film, el juicio conocido como "Sepur Zarco", celebrado en 2016 y cuyo nombre alude lugar donde operó una base militar destinada a la esclavitud sexual de mujeres de la etnia q'eqchí. Cabezas Vargas (2021) y Ramos Alquezar (2021) han

\footnotetext{
${ }^{5}$ Las víctimas pueden obtener medidas reparativas a través del Programa Nacional de Resarcimiento, y como consecuencia de sentencias judiciales nacionales como de la Corte Interamericana de Derechos Humanas. Aquel programa carece de una perspectiva de género y tiende a revictimizar a las víctimas mujeres. En general, las medidas reparativas han sido escasas. El Estado ha incumplido las sentencias judiciales y aquel programa solo ha dado medidas económicas modestas al $16 \%$ de las víctimas. Ver pp. 5, 47 y 48 del informe Las reparaciones para víctimas del conflicto armado en Guatemala: una promesa por cumplir.
}

Cuadernos del CILHA n $34-2021$ 
establecido que la memoria de este segundo proceso también se encuentra implicada en La Llorona. Además de la temática en torno a agresión sexual y su enjuiciamiento, me parece que el uso de los textiles indígenas, como explicaré más adelante, guarda relación especialmente con este segundo proceso.

Por lo tanto, para efectos de análisis del film objeto de estudio, es necesario considerar la importancia simbólica de ese proceso respecto de la consecución de una justicia transicional en Guatemala. De ahí podría explicarse que, en un país con escasa tradición cinematográfica, los filmes Nuestras Madres (2018) de César Díaz, La Llorona (2019) de Jayro Bustamante y el documental El Buen Cristiano (2016) de Izabel Acevedo se articulan en torno al tema de la memoria y el proceso contra Ríos Montt, y constituyen un novedoso espacio de reflexión sobre la justicia transicional ${ }^{6}$. En el caso particular de la película La Llorona, a mi modo de ver, tanto las representaciones de subjetividades de género implicadas en ese proceso penal, como las limitaciones antes discutidas sobre el carácter precario de la reparación, integran dos ejes fundamentales que desembocan en una relectura de la mitología de la Llorona.

\section{Las mujeres y lo religioso en la casa del General Monteverde}

El film se inicia con un murmullo en oscuras que gradualmente se va reconociendo como un rezo coral. La cámara empieza a enfocar una mujer avanzada en edad y blanca que ora y, paulatinamente mediante un travelling en retroceso acompañado de la subida de volumen, el espectador contempla un conjunto de mujeres de clase alta, que invocan protección divina "ven por nosotras, oye por nosotras, habla por nosotras, [...] haz por nosotras, ven a nosotras, camina con nosotras, habla por nosotras, haz por nosotras, escucha por nosotras, tráenos, llévanos, tráenos, llévanos" (1:34-1:36/1:39-

\footnotetext{
${ }^{6}$ Estos cineastas tienen en común haber vivido la infancia y la adolescencia durante el conflicto armado, cuyos años de mayor intensidad se localizan entre 1978 y 1989, y el haber alcanzado la edad adulta en los años de la llamada posguerra, caracterizada por la desigualdad social y la violencia. Díaz, Bustamante y Azevedo se unen a otros nombres que ya permiten hablar del nuevo cine guatemalteco. Son ellos: Sergio Ramírez, quien ha dirigido Distancia (2019) y 1991 (2021), Camila Urrutia, directora de Pólvora en el corazón (2019) y Ana Bustamante, directora del documental Asfixia (2018). Por su parte, Jayro Bustamente dirigió anteriormente Ixcanul (2015) y Temblores (2019). La mayoría de estas producciones han recibido reconocimientos internacionales. Por otra parte, para ver una cronología de las producciones fílmicas después de firmados los Acuerdos de Paz, ver A. Cabezas Vargas, "La Llorona de Jayro Bustamente: el ímpetu de las nuevas generaciones del cine guatemalteco".
}

Cuadernos del CILHA n $34-2021$

ISSN 1515-6125 | EISSN 1852-9615

6

CC BY-NC 2.5 AR

http://revistas.uncu.edu.ar/ojs/index.php/cilha/ 
1:49). Son las mujeres que forman parte de la familia y del círculo del general Enrique Monteverde. La mujer que ocupa el lugar central y que dirige la letanía es la esposa del general, Carmen, interpretada por la actriz de teatro mexicana Margarita Kenéfic. A su lado, se encuentran Natalia y Sara, hija y nieta respectivamente de Monteverde.

El peso de lo religioso y sobrenatural alude en esta primera escena a las prácticas neo pentecostales en el seno familiar, que fueron parte de la transformación social urbana y rural durante los años del conflicto armado. Aunque como sostiene la antropóloga Claudia Dary (2019), la versión dominante de la expansión neo pentecostal en Guatemala es haber sido un instrumento de la derecha cristiana norteamericana para influir en las mentalidades de la población, la conversión en los años ochenta supera este relato. El alivio espiritual, el mejoramiento económico, la posibilidad de construir redes sociales frente a la ausencia del Estado, así como un sentido de horizontalidad comunitaria sin elites intermediadoras, fueron otros factores que propiciaron que hoy en Guatemala quienes se definen como "cristianos no católicos" sean el $41 \%$ de la población. En el contexto de la ciudad, Dary (2019) indica que "las mujeres se vuelven expertas en organizar células de estudio en sus casos y luego, en articular redes de grupos por las diferentes zonas de la ciudad. Su trabajo va más allá del estudio bíblico y se extiende a la consejería personal en casos de problemas familiares" (Dary, 2019, p. 191). De ahí que este inicio del film represente con verosimilitud estas subjetividades femeninas urbanas, cuyas oraciones conjuntas, consejería y complicidad emocional fundan una versión de la realidad en la que lo religioso es el pilar central. Por lo tanto, desde esa complejidad religiosa explicada por Dary (2019), creemos que esta escena no debe reducirse a una supuesta representación del "oscurantismo de la clase dominante" (Bloch-Robin, 2021, p. 168).

Esta escena forma parte de la primera secuencia del film, definida por los momentos previos a las audiencias que debe enfrentar el general Monteverde. En tal sentido, el desplazamiento de la cámara de la sala donde oran las mujeres a la biblioteca de la casa marca la configuración de un discurso masculino basado en el heroísmo. En esa biblioteca, camaradas militares y el abogado defensor del General repasan las estrategias para asumir el proceso de genocidio, siendo la consigna clave "bajo ninguna razón agachen la cabeza" (3:58). Ellos saben que si cae el general, caen todos. De tal 
manera, una escisión clara a nivel de género durante el film y que ya se anuncia desde el inicio, es la colocación de las mujeres en la esfera de lo religioso.

La división antes mencionada es menos clara en la servidumbre de casa. Por un lado, la empleada fiel indígena, de nombre Valeriana, (interpretada por María Telón), reza antes de dormir desde un sincretismo religioso cristiano y maya. Este sincretismo, que incluye persignarse pero a la vez la utilización de símbolos mayas, alude a prácticas tradicionales, desde la terminología de José Roberto Morales (2007). Es decir, en estas prácticas tienen lugar expresiones de la espiritualidad ancestral maya y expresiones religiosas católicas cristianas que evidencian una "capacidad de inclusión, de adaptación y de resistencia" (Morales, 2007, p. 270). Este sincretismo se diferencia de otras prácticas modernas y posmodernas en el seno del movimiento maya del siglo XXI que postulan dejar cualquier expresión católica cristiana en pos de una autenticidad (Morales, 2007). La religiosidad sincrética de Valeriana se distancia, entonces, de estas prácticas mayas ligadas a una reivindicación política identitaria, $\mathrm{y}$, al hacerlo, posibilita en la trama de la película una futura cohesión interétnica y de clases en el espacio de la casa.

Ahora bien, los demás empleados, hombres y mujeres, reconocen una dimensión sobrenatural en esa casa, esto es, algo más allá del universo observable. Se trata del quejido de una mujer que el General ha escuchado en la noche y que provoca que él, armado de una pistola, dispare a la supuesta fantasma. Mientras Carmen y Natalia están convencidas de que es una pesadilla, los empleados afirman entre ellos, en lengua cakchiquel, que "es ella" (12:33). Valeriana que funge como intermediaria entre las patronas y los empleados niega en español aquella versión frente al General y a su familia, sin embargo, al día siguiente de esa noche confusa, ella anuncia la partida de todos los empleados. Afirma que "todos tienen miedo" (14:25). La estampida de la servidumbre hace que toda posibilidad de interpretación de origen maya sobre la realidad quede únicamente ejercida por las mujeres: Valeriana, que ha servido durante muchos años en la casa, y Alma, la nueva empleada doméstica que está por llegar. Con ello, se completa una identificación entre subjetividad femenina y creencia religiosa/sobrenatural en el espacio más importante del film: la casa del general Monteverde. 


\section{Mujeres indígenas en el foro judicial: la memoria prostética del juicio contra Ríos Montt}

La escena sobre la testificación en el foro judicial es la que se ajusta a una mayor retórica realista del film y la que probablemente genera una mayor memoria prostética. Para Alison Landsberg (2004), esta memoria se construye a través de tecnologías culturales (como el cine) que posibilitan experimentar como propios acontecimientos del pasado, no derivados de las experiencias directas sino de las imágenes. De tal manera, esa memoria prostética tiene la habilidad de producir empatía, así como alianzas políticas que trascienden raza, clase y género. Nos parece que esta escena ficcional, visto el éxito del film, ostenta posibilidades de mayor circulación global que los archivos visuales del juicio ${ }^{7}$.

Entonces, ¿cómo se construye esa memoria respecto de las mujeres indígenas víctimas del genocidio? En primer lugar, una figura clave en esta escena es la mujer testimoniante y dos elementos concomitantes a ella: el velo y el sentimiento de la vergüenza. Respecto del velo, un primer cubrimiento de la identidad en la ficción cinematográfica tiene lugar cuando, a diferencia de los personajes femeninos en la casa del General que tienen nombre propio, la mujer testimoniante en el juicio en contra del general Monteverde es anónima. Se identifica con el número de testigo 87. A nivel de interpretación, la actriz no forma parte del elenco principal y su nombre solamente es accesible en los créditos finales: "mujer ixil, María Marcos" (1:31:17). Se trata de una testiga, como otras, de la que se retendrá más el relato de horror que la individualización. Un segundo cubrimiento está ligado a los textiles. La testiga aparece vestida con un traje maya y particularmente con el rostro cubierto por un velo majestuoso semitransparente con brocados dorados. Según comunicación personal con Sofía Latán, encargada del vestuario de la película, ese traje pertenece al pueblo de Nebaj, en el Departamento de El Quiché -parte de la zona ixil donde se llevó a cabo el genocidio- y, consecuentemente, la elección "fue un homenaje a las mujeres ancestrales" que sufrieron la violencia en el conflicto armado. Sin embargo, tal elección

\footnotetext{
${ }^{7}$ Para el segmento de la película referente al juicio, el director Jayro Bustamante indicó que se llevó a cabo una labor de documentación con base en los archivos existentes, incluidos los documentales Cuando las montañas tiemblan (1983) de Pamela Yates y El buen cristiano (2016), de Isabel Azevedo. Ver Cabezas Vargas, A., 2021, p. 83.
} 
es más compleja en cuanto a la materialidad y valor simbólico del velo. Me refiero a que, en el proceso de genocidio contra Ríos Montt y en el llamado "Zepur Zarco" por esclavitud sexual de mujeres quekchíes en una base militar, fue una decisión de las testimoniantes el cubrirse el rostro con un perraje de uso cotidiano y los enfoques de las cámaras rara vez fueron de frente. De acuerdo con entrevistas en los medios ${ }^{8}$ y en el campo de la investigación científica, se adujo aquella decisión por miedo a la mirada de los acusados y al propio encubrimiento identitario de los soldados agresores:

Así hicieron aquellos cuando llegaron a sacar a nuestros esposos ¿acaso dejaron su cara descubierta? [...] Entonces eso es lo que queremos hacer nosotras también, porque no sabemos si los familiares nos van a perseguir o buscar, queremos tener mayor seguridad. Sí vamos a usar nuestro traje pero vamos a tapar nuestro rostro. (Margarita Chub Choc y Demesia Yat citadas por Amaya Rossi, 2018, p. 88)

A esta versión, se agregó en otros relatos mediales la vergüenza como razón del rostro oculto (ver nota 7). Esta es la narrativa del film, en la que se descarta la relación entre identidad oculta y el miedo a la persecución, y se afirma, en su lugar, el uso de aquel velo como la experiencia de la vergüenza. Frente a la cámara, y siempre con la intermediación de un traductor al español, la mujer testimoniante se quita el velo al final del testimonio como un gesto simbólico de clausurar la vergüenza y de interpelar a los jueces en el acto de impartir justicia: "A mí no me da vergüenza venir a contarles lo que viví, espero que a ustedes no les de vergüenza hacer justicia" (18.38-19.03). La

\footnotetext{
8 Por ejemplo, en el reportaje investigativo "La justicia de los perrajes" de Oswaldo Hernández, la psicóloga Maudi Patal que acompañó a las víctimas del caso Sepur Zarco, indica "Ellas pidieron el rebozo. Es una medida de protección ante la mirada de los acusados que a veces es muy penetrante, cargada de odio. Ellas saben que es importante comprender que no son culpables. $Y$ que ese sentimiento transmitido a los culpables, son los que ahora sentirán vergüenza". En ese mismo artículo, Amandine Fulchirone, autora del libro Tejidos que lleva el alma, puntualiza: "las mujeres que ha visto a lo largo del juicio de Sepur Zarco no son las mismas que recuerda cuando las conoció: fuertes, que no necesitaban ocultarse para hablar." En tal virtud, Fulchirone concluye que detrás de los perrajes yacen historias complejas y contradictorias. Oswaldo Hernández sostiene que también en esos perrajes existe una "representación de la ruptura de un contexto comunitario. El recuerdo: la culpa. El testimonio: el susto. La violación sexual: el abuso." Por lo tanto, la protección ante los perpetradores, la complejidad de la memoria, el narrar en el foro judicial y la carga de una culpa ligada al trauma fueron las versiones mediales sobre el uso de los perrajes. Este artículo periodístico las resume.
}

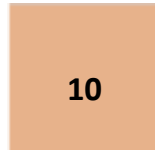

Cuadernos del CILHA n $34-2021$

ISSN 1515-6125 | EISSN 1852-9615

CC BY-NC 2.5 AR

http://revistas.uncu.edu.ar/ojs/index.php/cilha/ 
memoria prostética que se realiza en esta escena, distinta a la "memoria comunicativa" que nace de la propia biografía de las personas y que se produce en el marco de una interacción viva y social (Assmann, 2008), da predominancia, entonces, al velo como un gesto simbólico y escenográfico ligado a una transferencia de la liberación de la vergüenza, de la víctima al aparato judicial nacional. Aquí me parece importante la discusión de Sarah Ahmed (2017) sobre la retórica de la vergüenza nacional en cuanto "expone a la nación, y a lo que ha ocultado y cubierto con su orgullo, pero al mismo tiempo, involucra una narrativa de recuperación a recobrar/ re- cubrir a la nación" (p. 178). En este caso, viniendo de la víctima, el reclamo a dejar la vergüenza implica que ha existido una ocultación del sistema judicial frente a los delitos del conflicto armado en contra de las mujeres indígenas (impunidad/amnistía) y, a la vez, se abre la posibilidad de recobrar o recubrir esa nación en el acto de la justicia, que sería la sentencia condenatoria y la reparación. La posición de la cámara que pone al espectador en el lugar de los jueces refuerza aquel reclamo (Coto-Rivel, 2019). Por su parte, la majestuosidad del velo, a través del cual se puede ver el rostro de la testimoniante porque precisamente no hay miedo sino vergüenza, funge como una frontera que cae con la promesa de otra nación, una vez rendido el testimonio. Ese velo, por definición móvil, dúctil y no claro, podría leerse asimismo como una frontera étnica a través de la cual las identidades se sospechan, se vislumbran tímidamente. En cuanto a la vergüenza que podría derivarse específicamente del crimen sexual, esta queda latente en la película, pero no se ahonda en la misma.

Por otra parte, para Diane Bracco (2021), el despojarse del velo es una metáfora "desvelo literal" - en cuanto las mujeres ixiles "toman la palabra, en su propia lengua, para revelar las violaciones sufridas" (Bracco, 2021, p. 109). Correlacionado con ello, nos parece que la escena del foro judicial resulta en una afirmación simbólica de la importancia judicial, epistemológica y literaria del testimonio. Mediante el mismo procedimiento de travelling en retroceso, el espectador se percata de dos presencias fundamentales en la primera fila de la sala judicial: la premio nobel Rigoberta Menchú y la antropóloga Alejandra Colom, que en la ficción hace el papel de periodista y quien fue también productora asociada del film. De estas presencias autorreferenciales que componen un narrativa metadiscursiva dentro del film, resulta la validación de una alianza étnica y política en la memoria cultural (no comunicativa, insisto) del juicio. Se trata de remarcar la importancia de la antropóloga blanca y de la informante nativa 
maya en la consecución de una justicia transicional, y tal reforzamiento adquiere su punto más alto en el gesto de tomarse de las manos después del fallo condenatorio.

Ahora bien, para la lectura final de esta escena resulta oportuna la información que proporciona el director Jayro Bustamante en una entrevista:

Una cosa interesante de esta escena del juicio fue que, cuando leímos el guion y empezamos a trabajar la escena en los ensayos, la actriz que da testimonio me pidió si podía cambiar ciertas cosas del texto, porque la escena se parecía tanto a lo que ella había vivido que, si le cambiábamos estas escenas, se las podría apropiar mejor. Todas las personas que están trabajando en esta escena como actores de apoyo, todas están buscando a sus desaparecidos, hacen parte de organizaciones que están buscando a los desaparecidos, que trabajan en derechos humanos. De alguna manera, estamos muy cargados de energía en esa escena. (Kabous, 2021, p. 200)

Así pues, en la ficción cinematográfica se produce un testimonio factual y una de las oyentes es Rigoberta Menchú. Resulta inevitable que su presencia no solo apele a un icono global sino también a la genealogía del testimonio "literario", y particularmente, a la discusión fundacional que se estableció sobre la representación de la voz de los sujetos oprimidos y la intermediación del intelectual. Pareciera entonces que en esta escena, en la cual como informa Bustamante los actores de apoyo tienen alguna relación con las víctimas del conflicto armado ${ }^{9}$, revelarse /quitarse la vergüenza sea un momento culminante de fusión de distintos relatos testimoniales y la afirmación simbólica de la validez referencial de todos ellos en la consecución de una verdad y una justicia colectiva. Se trata, entonces, de un desvelo literal en la lengua, pero también de un desvelo en el discurso para legitimar la voz del oprimido, discurso en el que resulta insustituible la figura del intelectual blanco como intermediador. De nuevo, las manos tomadas de Rigoberta Menchú y Alejandra Colom enlazan esta alianza. Estamos frente a una imagen que constituye una tecnología de la memoria cultural en el sentido dado por Marita Sturken, a las imágenes, objetos y representaciones que no son "vessels of memory in which memory passively resides so much as objects through which

\footnotetext{
${ }^{9}$ Ver al respecto “Cómo la película de terror 'la Llorona' amplifica el mensaje de la activista indígena Rigoberta Menchú Tum".
} 
memories are shared, produced, and given meaning" (9). Así, en esta escena, se da sentido a una memoria cultural en donde el acto de testificar antropológico, literario y judicial en Guatemala ha sido fundacional en la historia intelectual latinoamericana ${ }^{10}$. Tal acto se construye en el film a partir de alianzas étnicas y políticas que propiciarían una justicia transicional y una posible verdad que refunde la nación.

\section{Sirvientas y espacio doméstico}

Cuando el fallo condenatorio es anunciado por una voz articulada en el discurso medial, el espacio vuelve a ser el espacio doméstico, apenas con una transición: el traslado del general y su familia a la casa bajo el asedio de los manifestantes. Es el momento de mayor ira en el film en el que se reconocen los familiares de desaparecidos, de origen ladino e indígena. Esta colectividad que protesta no dejará de plantarse con sus consignas delante de la casa del General.

En ese contexto, la estampida de la servidumbre permite la entrada de Alma, la sirvienta que encarnará el mito de la Llorona. Este personaje se ajusta a la percepción social dominante guatemalteca sobre las indígenas, tal como plantea la antropóloga Aura Cumes (2012):

Cotidianamente no se ve a las mujeres [indígenas] como sujetas pensantes sino como hacedoras "por naturaleza" del trabajo manual "no calificado". En otros términos, el lugar de las mujeres indígenas es el de sirvientas. Esto se mezcla con un tratamiento de su imagen como ornamento en tanto "objeto turístico". Es tan profundo este imaginario que las prácticas que lo reproducen con discursos que lo critican. (Cumes, 2012, p. 2)

\footnotetext{
${ }^{10}$ Karen Saban (2020) sostiene: "Es a partir de las memorias de Rigoberta Menchú, transcritas por Elisabeth Burgos-Debray, Me llamo Rigoberta Menchú y así me nació la conciencia (1983), que el testimonio empieza a ocupar el centro del debate intelectual. La controversia, basada en la doble autoría del texto entre testimoniante y entrevistadora, puso por un lado en entredicho la validez referencial del relato, mientras que, por otro, sentó las bases de un modo progresista y solidario de compromiso intelectual con las clases marginales (Oberti, 2015, p. 484)" (p. 280).
} 
Es decir, otras opciones de representación podrían haber girado en torno a la intelectual maya y/o la activista maya, tan presentes en la Guatemala contemporánea y en la reflexión sobre las identidades mayas y la memoria. Pienso, por ejemplo, en un espectro de pensadoras, activistas y artistas, como Sandra Xinico Batz, María Aguilar Velásquez, Gladys Tzul Tzul, Marilyn Boror, Rosa Chávez, Sandra Monterroso, Angelina Aspuac, esta última actora fundamental en el Movimiento Nacional de Tejedoras. Frente a estas identidades, el personaje Alma asume el lugar de la sirvienta. Con ello, se abre la interrogante si tal elección reproduce finalmente el rol reductivo de la mujer indígena o se articula una crítica al sistema de dominación doméstico.

Una primera consideración se refiere a cómo en la figura de Alma se intersectan el mito de la Llorona y el de la Siguanaba, tal y como lo examina con mucha precisión Paola García (2021). Si la Llorona es la mujer que ahogó sus hijos al ser abandonada por el marido y recorre, vestida de negro y en llanto, lugares acuáticos por la culpa, la Siguanaba encarna la mujer que vestida de blanco y de larga cabellera, seduce los hombres infieles, quienes al acercarse a ella, descubren un rostro de bestia. La Siguanaba también deambula en lugares asociados al agua. Con esta fusión de figuras, García (2021) argumenta que el director evita el machismo que se desprende del relato de la Llorona ${ }^{11}$. Por lo tanto, el elemento acuático es fundamental en la película: chorro abierto y pisos inundados de agua que anuncian la presencia espectral de la víctima, la piscina cubierta con rostros de desaparecidos y luego hábitat para los sapos que traen el alma de los muertos, la bañera en donde Alma atrae al General, el propio General que necesita una máscara de oxígeno, la apariencia de una Alma mojada, la humedad que sube por las paredes del cuarto del general y que agrava su condición. Mayoritariamente el elemento acuático significa el espacio de la venganza de Alma en cuanto acerca o concreta la muerte del culpable y hace presente la memoria de las víctimas, pero también cumple un papel de acompañamiento leal a la nieta del General, cuyo reto es aguantar la respiración bajo el agua. Alma acompaña y cuida a Sara en sus intervenciones en el agua y, en un momento supremo, le pide que no se ahogue. Aquí,

\footnotetext{
${ }^{11}$ La presencia del mito de la Siguanaba en Alma es fundamental en cuanto a su aspecto seductor con relación al general Monteverde. Paola García (2021) indica: "La seducción se pone en marcha desde el comienzo: el general se siente irremediablemente atraído cuando fe a Alma recoger los afiches de los manifestantes en la piscina y el uniforme pone de relieve su cuerpo. El general la vigila magnetizado desde el balcón. La etapa siguiente es observarla mientras se baña en la piscina y luego seducirla [...]" (p. 47).
}

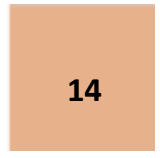

Cuadernos del CILHA n $34-2021$

ISSN 1515-6125 | EISSN 1852-9615

CC BY-NC 2.5 AR

http://revistas.uncu.edu.ar/ojs/index.php/cilha/ 
desde la perspectiva de García (2021), opera una memoria reconciliadora: "Si Sara, la generación futura, acaricia la rana es porque ha aceptado conocer el pasado tal y como lo vivieron y contaron las víctimas. Sara con sus pruebas de apnea intenta dominar el peligro del agua y fortalecerse" (p. 46). García (2021) agrega que Sara desea imitar a Alma y que parece convertirse en "un alter ego" de ella o de sus hijos.

Nos parece, sin embargo, que la lectura de una memoria reconciliadora en la relación entre Alma y Sara opera con varios límites. En primer lugar, en Sara no reside la generación futura, sino una sección muy particular de esa generación: los nietos de los militares. En clave referencial, sería la nieta de algún miembro de la Asociación de Veteranos Militares de Guatemala. Es decir, la posibilidad representacional colectiva de Sara no es tan amplia, incluso con la sospecha de un padre desaparecido. Educada en la familia del General, más bien, el personaje de Sara tiene un poder de representación limitado, como sería por ejemplo, respecto de los nietos de la clase trabajadora, los nietos de campesinos, nietos de una clase media disidente de la élite militar. En segundo lugar, el cuido de Alma sobre Sara reinscribe la labor más tradicional de la sirvienta: ser incondicional a los hijos de los patronos. El documental de Marcela Zamora Las muchachas (2013), en tal sentido, resulta ilustrativo en cuanto plantea un conflicto moral central en las trabajadoras domésticas: la entrega a los hijos ajenos y la renuncia obligada a cuidar los propios. La declaración de una de ellas así lo plantea: "Yo me sentía mal por el amor, la atención y la paciencia que yo les daba a los hijos ajenos y no se las daba a mis hijos" (Zamora, 2013, 26:50). Este conflicto en el film sería más radical, porque los hijos de Alma han sido ejecutados. Sin embargo, en el film se erige la imagen de la comunicación paciente, de una bondad sin fisuras ante Sara, bondad desprovista de malestar de parte de Alma. Varias escenas estampan esa maternidad delegada asumida por las sirvientas centroamericanas, de tal manera que las y los hijos de los patronos llegan a poseer una mayor intimidad afectiva con ellas, eso sí, sin que las condiciones laborales o una retribución justa al final del servicio tengan lugar. Es lo que pasa en el film.

Volviendo a la idea planteada por García (2021) de la memoria reconciliadora, tanto en el acto en que Sara se acerca a Alma para acariciar el sapo entre las manos de aquella como también en un supuesto querer convertirse en Alma -“la niña (Sara) parece convertirse en el alter ego de Alma" (p. 49)-, hay sobretodo un reforzamiento del 
tradicional rol de cercanía entre la empleada doméstica y los niños de la casa. Cuando Sara se acerca al sapo, no sabe de ningún valor simbólico, es la curiosidad que la lleva a acercarse a él. Cuando Sara conoce a Alma y le dice a Natalia "¿Me puedo dejar el pelo largo y usar un vestido como el de ella?" (35:06-35:11), hay que considerar que Alma no lleva todavía el traje tradicional maya con el que en Guatemala se identifica la identidad indígena sino una túnica blanca. Se lo pondrá, luego, cuando Carmen la obligue a ponerse el traje maya - "tu traje"- en lugar del uniforme, adjudicando a este último la provocación sexual al general Monteverde ${ }^{12}$. Por lo tanto, lo que experimenta Sara, cuando conoce a Alma, es una atracción por lo distinto: un animal en la casa (sapo) y los códigos de vestimenta inusuales representados por una túnica blanca. Alma es, entonces, una sujeta exótica en este momento y de ahí la gana de imitación, que a su vez se encuadra en la atracción peligrosa de un relato de horror. No hay que olvidar, además, que la pregunta sobre la imitación se realiza cuando la familia ha presenciado al guardaespaldas cachear a Alma. Ella constituye, entonces, objeto de revisión corporal, objeto de escrutamiento, objeto atractivo a ser imitado.

Si en la escena judicial, metadiscursivamente, la antropóloga blanca ocupa una presencia fundamental en el relato transicional de la justicia, en la casa, la niña blanca, que pregunta si lo que circula en internet es la verdad sobre su abuelo y prueba la resistencia bajo el agua, se presenta como una aliada potencial en aquella justicia. Frente a esta niña, la sirvienta indígena/fantasma se autoformula dadivosa. De ahí que, de alguna manera, Sara sí apela a una memoria reconciliadora, pero para que sea posible el personaje indígena tiene que cumplir un rol tradicional de sirvienta. El espacio doméstico, un lugar fundamental de jerarquías étnicas y sociales en Guatemala, aparece inalterable en el film, a no ser por un último acto religioso que es asumido en la desesperación de los habitantes de la casa.

\footnotetext{
12 Después del ingreso en la casa con la túnica blanca, Alma usa el uniforme de empleada doméstica. Luego de que el general Monteverde tratara de agredir sexualmente a Alma, en una atmósfera onírica de horror, Carmen asume una actitud tradicional y patriarcal. Según ella, Alma ha provocado al General y, de ahí, el tercer cambio de vestimenta: "A partir de mañana, ya no vas a usar el uniforme. Te queda muy ceñido. Ponete tu traje" (54:11-54:16).
} 


\section{El exorcismo: infiltración del fantasma y restauración del orden}

La última parte de La Llorona se centra en la construcción de Alma como la figura del fantasma que invade progresivamente la casa del General Monteverde y trastorna las relaciones entre sus habitantes, activando una memoria perturbadora para las mujeres blancas de la familia Monteverde. Se reafirman las dudas de Sofía sobre la desaparición del padre de Sara y, sobretodo, Carmen está asediada por las memorias de la depredación sexual de Monteverde respecto de las mujeres mayas. En esas memorias, queda claro para Carmen que Valeriana es hija del General.

Estas memorias implican una decadencia corporal en Carmen, la cual es interpretada con una gran maestría por Margarita Kenéfic. Así, por ejemplo, Carmen empieza a sufrir de conjuntivitis por la humedad de la habitación y se orina en la cama, cuando sueña que, vestida de blanco como Alma, huye entre los maizales con dos niños indígenas ante el asedio militar. Natalia le provee de pañales en caso de otro accidente. Considero que este proceso de enfermedad y limitaciones físicas produce una empatía en el espectador. Si Carmen finalmente se acerca a ver a quienes protestan afuera de su casa, paralelamente pareciera que se interpela al espectador a sentir misericordia por esta mujer empequeñecida que, por la presencia de la Llorona, se vuelve más humana. La actuación convincente de Kenéfic refuerza esta interpelación afectiva del espectador. Importante en este proceso es que la clave religiosa, definitoria desde la primera escena, sigue rigiendo el entendimiento de Carmen. Cuando Carmen ya no tiene dudas de que Valeriana es hija del general afirma a Natalia: "Tal vez es una bendición que me mandó el cielo porque qué haría yo sin ella" (58:38-58:42). Las mujeres en la casa del General no pueden interpretar el mundo fuera de la fe, sea cual sea esta.

El momento culminante del film, ya anunciado en las pesadillas de Carmen, ocurre cuando en la noche, como otra de las noches perturbadoras en el film, los espectros de los desaparecidos y/o de sus familiares que no han dejado de protestar afuera de la casa, han entrado en el jardín. Se oye el llanto de una mujer y Sara aclara que es Alma quien llora a sus hijos porque le contó que, desde mucho tiempo antes, conoce al General. El carácter atemporal y fantasmagórico de Alma apresura un rito conducido por Valeriana, en torno a velas y la invocación de los espíritus ancestrales. En la oración proferida por Valeriana, resulta fundamental reconocer que ella atribuye una 
culpabilidad al general y, en la contraparte, se declara la inocencia de un nosotros, constituido por las intervinientes en la ceremonia: Carmen, Natalia, Sara y Valeriana: "If the General has a debt with you, please understand we had nothing to do with it" $(1: 24: 26-1: 24: 31)$.

Es decir, la complicidad no puede existir en estas mujeres. La ceremonia va en crescendo y entonces Carmen experimenta una metempsicosis y, como ya se ha anunciado en sus pesadillas, ella es Alma que huye con sus hijos de los militares. En este proceso de identificación con Alma, Carmen presencia cómo los hijos de Alma/sus hijos son ahogados en el río y cómo Alma es disparada en la frente por Enrique Monteverde. Carmen asesina entonces a Monteverde. Según Ramos Alquezar (2021), se produce una posesión que “[...] al final la justicia habrá sido ejecutada por los vivos, los más próximos, en un exorcismo que se acaba imponiendo como doble espectral del juicio, resuelto además por un grupo de mujeres, entre las cuales se cuenta una indígena" ( $p$. 101). De tal manera, y aquí la última gran alianza simbólica del film, las propias mujeres, tanto la indígena y las blancas, han resuelto su condición de sujetas amenazadas y su propios mundos internos convulsos en el plano religioso, porque es el único en el que realmente confían. No existe justicia estatal y laica, sino la misma es planteada en términos de ceremonia religiosa doméstica, con lo cual el film reafirma la fe como una narrativa central en la ciudadanía guatemalteca. La reparación de la vida cotidiana de la testimoniante maya, de la que no sabremos el nombre, resulta inexistente.

Quiero finalmente detenerme en el proceso de identificación de Carmen con Alma. Para ello me refiero brevemente a la película norteamericana Time to Kill (1996), en torno al sur de Estados Unidos, la justicia y las identidades raciales. En esta película, un abogado blanco trata de convencer al jurado de que declare la inocencia de un padre afroamericano quien, después de que su hija fue violada salvajemente por dos hombres blancos, los asesina al percatarse que difícilmente serán condenados. La empatía en torno a la paternidad impulsa a que el abogado blanco tome el caso. En la escena final del juicio, la estrategia del abogado blanco es pedir al jurado que cierre los ojos mientras él relata esa violación. Al terminar, les pide que imaginen que esa niña violada es blanca. El jurado, mayoritariamente compuesto por blancos, exculpa al padre afroamericano. Como sostiene Donald Bogle (1999), este film forma parte de una corriente cinematográfica norteamericana de los 1980 y 1990 (influenciada por la era 
Reagan), que deja de lado el examen amplio del racismo del sur y las figuras rebeldes afroamericanas $y$, en su lugar, adquiere preponderancia el examinar cómo los personajes blancos entienden y experimentan la historia de los afroamericanos del sur. En este film, el abogado blanco es quien examina esa historia. Hélène Charlery (2011) concluye al respecto que:

[...] the race question is seen through the white character; the final summation marks the narrative victory of the white law-figure; the South's rednecks are eliminated from the story's conclusion which allows this redemptive tale to protect the rest of the southern white community; the characterization of the central black character supports the narrative construction of the white hero. All these support the film's conservative central purpose: constructing white male heroism by binding it to the conservative values of a family structure grounded on victorious and strong images of fatherhood. (s.p)

En el caso de La Llorona, propongo que lo que se refuerza con la ceremonia final es la familia como la vía de una reconciliación étnica en el ejercicio de la memoria. Se logra eliminar a Enrique Monteverde a cambio de la autoprotección de las cuatro mujeres frente al asedio de los espectros y también frente a la agencia histórica de quienes, con los rostros de los desaparecidos, no se dan por vencidos en reclamar justicia. ¿Dónde quedan ellos después de esta ceremonia? ¿Han logrado avanzar en sus reclamos? De acuerdo con la narrativa de La Llorona, esto no es rastreable ni representable. Incluso, aquellos indignados se erigen como un peligro que ha provocado la ceremonia maya de emergencia, dirigida por Valeriana. La religión (y con ello lo sobrenatural) como eje central de las identidades de las mujeres y la cohesión de la familia, no obstante las diferencias y jerarquías étnicas, son las que prevalecen para restaurar un orden que implica acabar con el ejecutor del mal, el general Enrique Monteverde.

Así pues, el film deposita una gran confianza en la conversión de las mujeres de una clase social alta y vinculada a los militares y menos explora la complicidad de las mismas. Se cuida que ellas, al final, sean víctimas: Carmen de las infidelidades de Monteverde, Natalia de la desaparición del padre de Sara por Monteverde, y Sara, asfixiada por el ambiente opresor de la casa. La rebeldía de los personajes indígenas resulta limitada. Es verdad que la Llorona aparece amenazante, lista para infiltrarse y 
desacomodar el orden de los asesinos, como se sugiere en la escena final, cuando otro militar ve el piso inundado por el agua. Sin embargo, la secuencia latente hace pensar que otra aparición de La Llorona desembocaría, a su vez, en otro rito privado para detener la amenaza de la verdad histórica. La mayoría de estudios sobre este film (Thibaudeau, 2021; Ramos Alquezar, 2021; Orellana, 2020) reivindican una justicia espectral en el film, desde las reflexiones de Jacques Derrida. Es decir, Alma encarna el espectro que observa, que vigila, que tiene el derecho de la mirada absoluta, testificando la violencia del pasado e impidiendo la legitimidad de la hegemonía de la que ha sido víctima. Según lo mencionado al inicio de este trabajo, esa presencia espectral viene a ser el efecto de una justicia transicional muy limitada respecto de las mujeres mayas víctimas del genocidio, no sólo por la anulación de la sentencia sino también por la ausencia de medidas reparativas. Una venganza espectral no puede cumplir el papel de reparación colectiva indispensable para superar el trauma. El espectro de la Llorona, con su poder mítico, por otra parte, al irrumpir y alterar el orden de dominación del patriarca, favorece finalmente la reparación de las mujeres blancas de clase alta, cercanas al poder militar.

Kirsten Mahlke, al estudiar la producción literaria y cultural fantástica relacionada con la dictadura argentina, detecta cómo tal género de lo fantástico puede convertirse en una experiencia mimética: "cuando la experiencia social bajo el terror del Estado (y mucho tiempo después) es una coexistencia con los desaparecidos fantasmáticos, escribir sobre los vengadores y los no muertos se convierte de repente en un género mimético" (p. 328). Es decir, el terror referencial y con él la figura del desaparecido trastocan las bases de un género basado en la transgresión de la realidad. Mahlke agrega que la figura del desaparecido y la práctica de la desaparición forzosa son ya "un paradigma de transgresión real-fantástico" (Mahlke, 2020, p. 332) y de ahí esa reconfiguración mimética. Con base en estas reflexiones, la desaparición de Alma en el film-de la cual ya no sabemos nada, ni un rastro-, se vuelve mimética del terror guatemalteco, y por tanto, supera la aparición y desaparición fantástica propia de las leyendas populares. Ni viva ni muerta, la Llorona desaparecida encarna quizás el verdadero terror del film. Deja de ser un espectro de leyenda popular para convertirse en la mímesis del borramiento, de la extracción cruel. El efecto de la represión y la violencia extrema. 


\section{Dónde están las ladinas}

Aunque el ámbito de este trabajo supera las discusiones sobre la identidad ladina en Guatemala, sí quiero referirme brevemente a la representación muy secundaria de las mujeres ladinas en el film que se analiza. Patricia Harms (2020) plantea que, en las investigaciones científicas sobre las mujeres en Guatemala, ha existido una tendencia a invisibilizar el papel de las mujeres ladinas en la historia de la nación. Tal tendencia puede ser atribuida a la propia identidad ladina: "The very identity of "ladina" has been another critical factor in obscuring the activism of urban women" (Harms, 2020, p. 5). Como establece Harms, la categoría ladina, que es exclusiva en su uso para Guatemala en el contexto centroamericano, resulta problemática de definir, pues no implica estrictamente el factor étnico, sino aparece marcada por factores económicos, sociales y políticos. Sin embargo, más allá de esta complejidad, Cecilia Menjívar aclara que lo ladino es un lugar intersticial en la nación guatemalteca "is a place in between the elite Spanish-speaking State and the indigenous communities" (Menjívar referida por Harms, p. 7) y, como consecuencia de esta situación, la ladinidad se alinea, disiente o se opone frente al Estado. El no uso de traje maya y la carencia de una lengua maya son dos rasgos fundamentales de la ladinidad. Desde hace algunos años, especialmente mujeres jóvenes han reclamado en Guatemala revisar esa categoría como un proceso de reflexión sobre la negación de lo indígena en la constitución de la ladina.

En La Llorona, tiene lugar una escisión binaria en los personajes: mayas pobres y los provenientes de una élite blanca. Las mujeres ladinas de clases medias y populares solo pueden ser percibidas fortuitamente en la juzgadora del caso contra el general Enrique Monteverde y como parte de la muchedumbre que protesta fuera de la casa. En la casa, no existen empleadas mujeres ladinas. Las dos escenas en donde aparecen los sirvientes en forma grupal -después del incidente en el que el General estuvo a punto de matar en la noche y cuando deciden irse- evidencian en el uso de una lengua maya común la exclusión de lo ladino. Pareciera entonces que la memoria reconciliadora que se adjudica a La Llorona se concentra en las subjetividades blanca y maya, de tal manera que las mujeres ladinas pasan a ser sujetas secundarias, aún cuando en el foro judicial y en la protesta popular son las que impulsan una justicia pública e institucional. Andrea Cabezas Vargas (2021) indica que una virtud de La Llorona es que "se inscribe plenamente dentro del cine denominado de memoria histórica en Guatemala, 
aportando una contribución a la reconstrucción de la Historia desde distintos puntos de vista" (Cabezas Vargas, 2021, 85). Cabezas Vargas atribuye ese cambio de perspectiva el devolver la dignidad a grupos sociales marginados. Nos parece, empero, que tal perspectiva en la película se restringe respecto de una muy limitada representación de la agencia histórica de las mujeres ladinas, validándose la aseveración de Patricia Harms (2021) sobre la dificultad de la visibilidad del activismo político llevado por ellas en distintos momentos de la historia fuera de la visión binaria maya y blanco de lo guatemalteco. Incluso, aquella devolución de la dignidad a que se refiere Cabezas Vargas no sería devolución propiamente respecto de las víctimas mayas, sino más bien el film deja en suspenso (mediante el suspense) una reparación que permitiera recuperar la identidad integral y la agencia de la víctima.

\section{Conclusiones}

Indudablemente, La Llorona forma parte de un momento epocal en Guatemala marcado por la polarización social y que, por tanto, apela a imaginarios y ritos memorialísticos y reconciliadores que, como hemos visto, son inseparables de la impunidad en el fuero judicial. Un momento culminante y vehemente de esa voluntad de memoria reconciliadora es la canción de La Llorona al final del filme. Esta versión es interpretada por Gaby Moreno, una voz musical femenina influyente en los estratos sociales urbanos guatemaltecos. La combinación de la chirimía, la marimba, el tum, los chinchines, el caracol y el violoncelo, aunada a la voz de Moreno, y la transnacionalidad musical del tema de La Llorona sellan una intención inclusiva y totalizadora en la memoria representada en el film ${ }^{13}$. Asimismo, la fotografía de María Mercedes Coyoy que promociona el film fue realizada por el conocido fotógrafo Daniel Hernández Salazar, con lo cual se potencia una articulación con un imaginario de recuperación de la memoria. El nombre de Daniel Hernández Salazar está vinculado a la realización de la emblemática portada “Memoria del Ángel” del proyecto REHMI. La Llorona conjuga, pues, una arquitectura cuidada para lograr horizontes de recepción que aseguren la

\footnotetext{
${ }^{13} \mathrm{Al}$ respecto, la letra de la canción reza "Todos Iloran/tu tierra Llorona/ tu tierra ensangrentada". Se refuerza la intención de convocar simbólicamente y coralmente a una colectividad, sin exclusiones, que compartan el dolor del duelo por la tierra, por la pérdida.
}

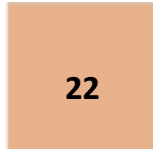

Cuadernos del CILHA n $34-2021$

ISSN 1515-6125 | EISSN 1852-9615

CC BY-NC 2.5 AR

http://revistas.uncu.edu.ar/ojs/index.php/cilha/ 
circulación de la película y hagan presente iconos, archivos y rastros del difícil proceso de trauma, memoria y justicia en la Guatemala del postconflicto armado.

La perspectiva de Jayro Bustamante sobre cómo el género fantástico podía atraer un público más amplio y joven, se cumple en los horizontes de expectativas nacionales e internacionales (Bracco, 2021, p. 128). Como hemos visto, este género fantástico permite articular una memoria espectral en la que la elite blanca, en clave femenina, queda a salvo, lejos de una complicidad por el genocidio. Menos visible es el hecho de que el espectro de Alma mimetiza el horror del desaparecido, y allí residiría el núcleo del terror de la película, más que en las amenazas, signos y trastocamientos que ha producido el fantasma en la casa. Lejos de esa casa que será reapropiada por Carmen, Natalia, Sara y Valeriana previsiblemente desde las mismas jerarquías domésticas de las señoras y las sirvientas que menciona Aura Cumes, está la testiga ixil, cuyo velo descubierto en el juicio apunta en clave retrospectiva a una interpelación fracasada a la nación. La anulación de la sentencia de la Corte de Constitucionalidad recreada en la película desde una voz periodística y televisiva supone que aquella testiga continúa su vida cotidiana, sin reparación, en la pobreza y posiblemente en la discriminación. Sus luchas y resistencias históricas exceden la estética y la historia del film.

\section{Referencias}

Acevedo I. (Directora) (2016). El Buen Cristiano. [Película]. Centro de Capacitación Cinematográfico.

Aguilar C. (2020). Cómo la película de terror 'la Llorona' amplifica el mensaje de la activista indígena Rigoberta Menchú Tum. Los Angeles Times.

https://www.latimes.com/espanol/entretenimiento/articulo/2020-08-19/como-la-pelicula-de-terror-laIlorona-amplifica-el-mensaje-de-la-activista-indigena-riboberta-menchu-tum

Ahmed, S. (2017). La política cultural de las emociones (C. Olivares Mansuy, Trad.). UNAM/Centro de Investigaciones y Estudios de Género.

Amaya Rossi, B. (2018). La construcción de la ciudadanía en las mujeres de Sepur Zarco, El Estor, Izabal (19822014). [Tesis de pregrado, Universidad Rafael Landívar].

http://recursosbiblio.url.edu.gt/tesiseortiz/2018/04/26/Amaya-Bettina.pdf

Assmann, A. (2011). Cultural Memory and Western Civilization: Functions, Media, Archives. Cambridge U.P. 
Benítez Jiménez, M. A. (2015). Frente al genocidio: justicia transicional y movilización en Guatemala. Revista Latinoamericana de Estudios de Seguridad, 16, 37-52

https://doi.org/10.17141/urvio.16.2015.1808

Bloch-Robin M. (2021). La voz recobrada de los silenciados en La Llorona de Jayro Bustamante. Pandora 16, 165-181.

https://etudes-romanes.univ-paris8.fr/IMG/pdf/pandora_web_final.pdf

Bogle, D. (1999). Toms, Coons, Mulattoes, Mammies, and Bucks. An interpretative History of Blacks in American Films. Continuum.

Bracco, D. (2021). Indio, hueco, comunista. Aproximaciones a la trilogía de Jayro Bustamante Pandora 16, 109-131.

https://etudes-romanes.univ-paris8.fr/IMG/pdf/pandora_web_final.pdf

Burt, J.-M. (2019). From Heaven to Hell in Ten Days: the Genocide Trial in Guatemala. Journal of Genocide Research 18 (2-3), 143-169. https://www.tandfonline.com/doi/abs/10.1080/14623528.2016.1186437

Bustamante, J. (dir.) (2019). La Llorona. [Película]. La Casa de Producción, Les Films du Volcan.

CEH. (1999). Memoria del silencio. http://www.centrodememoriahistorica.gov.co/descargas/guatemalamemoria-silencio/guatemala-memoria-del-silencio.pdf

Cabezas Vargas, A. (2021). La Llorona de Jayro Bustamante: el ímpetu de las nuevas generaciones del cine guatemalteco. Pandora 16, 71-88.

https://etudes-romanes.univ-paris8.fr/IMG/pdf/pandora_web_final.pdf

Coto-Rivel, S. (2019). Relaciones entre testimonio, memoria y ficción en La Llorona. Avec: E. Díaz (dir.), Épreuve de composition au CAPES d'espagnol session 2021 Jayro Bustamante La Llorona, 2019 (págs. 119134), Ellipses.

Cumes, A. (2012). Mujeres indígenas, patriarcado y colonialismo: un desafío a la segregación comprensiva de las formas de dominio. Anuario de Hojas de Warmi 17, 1-16. https://revistas.um.es/hojasdewarmi/issue/view/10841

Crosby, A. et al. (2016). Carrying a Heavy Load: Mayan Women's Understandings of Reparation in the Aftermath of Genocide. Journal of Genocide Research 18 (2-3), 265-283. https://www.tandfonline.com/doi/abs/10.1080/14623528.2016.1186952

Charlery H. (2011). Burning Mississippi: Race, Fatherhood and the South in A Time to Kill. Miranda 5, 1-15 https://doi.org/10.4000/miranda.2343

Dary, C. (2019). La explosión pentecostal: Perspectivas analíticas sobre la transformación religiosa en Guatemala. Ciencias Sociales y Humanidades. 6 (2), 85-99. https://doi.org/10.36829/63CHS.v6i2.828

Díaz, C. (Director) (2019). Nuestras madres. [Película]. Need Productions, Perspective Films.

García P. (2021). La Llorona de Jayro Bustamante: una interpretación mítica de la violencia. Pandora 16, 3753. 
Goldman, F. (2007). The Art of Political Murder. Grove Press.

Derrida, J. (1993). Spectres de Marx. Editions Galilée.

Hamber, B. (2009). Transforming Societies after Political Violence. Springer International Publishing.

Harms, P. (2020). Ladina Social Activism in Guatemala. University of New Mexico Press.

Hernández O. (2 de febrero de 2015). La justicia de los perrajes. Plaza Pública. https://www.plazapublica.com.gt/content/la-justicia-de-los-perrajes

International Center for Transitional Justice. What is Transitional Justice https://www.ictj.org/about/transitional-justice

Kabous, M. "Que viaje sea lindo", potencia estérica y significativa del encuadre y del travelling en La Llorona. Pandora, 16, 185-201.

https://etudes-romanes.univ-paris8.fr/IMG/pdf/pandora_web_final.pdf

Landsberg, A. (2004). Prosthetic Memory: The Transformation of American Remembrance in the Age of Mass Culture. Columbia University Press.

Latán, S. (comunicación personal, 13 de mayo de 2021).

Mahlke, K. (2020). El modo fantástico y las narrativas del terror. En R. Spiller et al (Eds.) Trauma y memoria cultural Hispanoamérica y España (pp. 321-336). Gruyter.

https://dx.doi.org/10.1515/9783110420760-020

Martínez. D., Gómez L. (abril, 2019). Las reparaciones para víctimas del conflicto armado en Guatemala: una propuesta por cumplir. Reparations, Responsability \& Victimhood in Transitional Societies

https://reparations.qub.ac.uk/assets/uploads/Guatemalan-Report-ESP-LR-1.pdf

Marcus, S. (1992). Fighting Bodies, Figthing Words: A Theory and Politics of Rape Prevention. In: J. Butler, J. W. Scott (Eds.), Feminists: Theorize the Political (pp. 385-403). Routdlege.

Morales, J.R. (2007). Religión y espiritualidad maya. En: S. Bastos, A. Cumes, A. (Eds.). Mayanización y vida cotidiana. La ideología multicultural en la sociedad guatemalteca. Vol. 3. FLACSO-CIRMA-Cholsamaj.

Oglesby E., Neslon, M. D. Guatemala's Genocide Trial and the Nexus of Racism and Counterinsurgency. $\begin{array}{llllll}\text { Journal of } & \text { Genocide } & \text { Research } & 18 & (2-3), & 133-142 .\end{array}$ https://www.tandfonline.com/doi/full/10.1080/14623528.2016.1186436

ODHAG (1999). Informe proyecto interdiocesano de recuperación de la memoria histórica. Tomo I, Impactos de la violencia.

Orellana, C. G. (2020). Espectros de justicia: reflexiones a partir de La Llorona de Jayro Bustamante. https://azacuan.com/titulares/reflexiones-a-partir-de-la-llorona-de-jayro-bustamante/ 
Ramos Alquezar, S. (2021) Justicia espectral: violencia política y género fantástico en el cine latinoamericano actual. Pandora, 16, 71-88.

https://etudes-romanes.univ-paris8.fr/IMG/pdf/pandora web final.pdf

Saban, K. (2020). El testimonio hispanoamericano. En: R. Spiller et al. (Eds.), Trauma y memoria cultural eh Hispanoamérica y España (págs. 279-292). De Gruyter.

Sturken, M. (1997). Tangled Memories: The Vietnam War, the Aids Epidemic, and the Politics of Remembering. Univ. Of California Press.

Thibaudeau, P. Umbrales, franqueamientos y flujos espectrales en La Llorona de Jayro Bustamante. Pandora 16, 135-148.

https://etudes-romanes.univ-paris8.fr/IMG/pdf/pandora_web_final.pdf

Zamora, M. (Dir.) (2013). Las muchachas. [Película]. El Faro. 